\title{
MODIFIED VOLTAGE CONTROL LAW FOR LOW FREQUENCY RAILWAY POWER SYSTEMS
}

\author{
John Laury * \\ Electric Power Engineering \\ Luleå University of Technology \\ 93187 Skellefteå, Sweden \\ Email: john.laury@ltu.se
}

\author{
Lars Abrahamsson \\ Electric Power Engineering \\ Luleå University of Technology \\ 93187 Skellefteå, Sweden \\ Email: lars.abrahamsson@ltu.se
}

\author{
Math Bollen \\ Electric Power Engineering \\ Luleå University of Technology \\ 93187 Skellefteå, Sweden \\ Email: math.bollen@ltu.se
}

\begin{abstract}
In today's Swedish and Norwegian low frequency railway power system the voltage at a converter is controlled such that its voltage will drop with increased reactive power output. However, for low frequency railways the influence of active power on voltage is larger compared to public power systems and alternative methods are interesting to investigate.

This paper presents a modified voltage control law for increased load sharing between converter stations and reduce the risk for converter overload in low frequency railways power systems. The modified voltage control law is derived mathematically and tested with different droops for two case studies. The results confirms the increased load sharing between the converter stations.

The results are analysed and discussed; ideas are presented to counteract some of the negative impacts of the modified voltage control law.
\end{abstract}

\section{INTRODUCTION}

Today, the countries of Norway, Sweden, Germany, Austria, Switzerland and the North East of the U.S. uses low frequency for their railway power systems [1]. Due to the different frequency used compared to the three phase public power system frequency conversion is needed.

The conversion between frequencies is done by using converters that can be either mechanical or power electronic based. The (mechanical) Rotary Frequency Converter (RFC) consists of

${ }^{*}$ Corresponding author. a three phase motor and a single phase synchronous generator mounted on the same mechanical shaft. The pole ratio between motor and generator is 3 and 2.4 for Europe and U.S, respectively, resulting in the desired frequency. The motor can be either a doubly fed induction motor or a synchronous motor. In central Europe the RFC motor is of a doubly fed induction type, resulting in asynchronous connection to the public power system. In Sweden, Norway and the North East of the U.S. the RFC motor is of synchronous type, resulting in a stiff frequency connection between the railway power system and the three phase public power system.

The (power electronic based) Static Frequency Converter (SFC) is either a direct converter or a self-commutated converter [2]. In Sweden and Norway the SFCs are controlled in such way that they mimic the steady state behaviour of an RFC regarding voltage angle and the magnitude of voltage at the railway side.

One of the main differences between the asynchronoussynchronous and synchronous-synchronous low frequency railway power systems is that the active power cannot easily be controlled in the latter system as in the asynchronous-synchronous system. The active power transfer from the three phase public power grid through a synchronous-synchronous RFC to the railway power grid, is determined by the voltage angle difference between the grids at the point of connections [3]. Control of active power in the low frequency railway power system in central Europe is done by implementing frequency droop control [4], as the induction motors are controllable. Common for all low frequency railway power systems is the application of voltage
Copyright (c) 2017 by ASME 
control on both converter types, i.e. RFC and SFC.

In today's Scandinavian converter-fed railway power system, the voltage at the converter stations and units has a linear dependency with the reactive power output. The voltage will increase or decrease with decreased or increased reactive power output, respectively. This concept is called voltage droop and originates in the $50 / 60 \mathrm{~Hz}$ electrical power system, where large generator units are operating in parallel in order to control a voltage at a certain location, and thus sharing the reactive power loading.

In the $50 / 60 \mathrm{~Hz}$ electrical power system the resistance is often neglected as it is much smaller than the reactance and therefore voltage is mainly dependent on reactive power. Thus, the traditional voltage control for railway power systems works well, when reactive power and voltage level are strongly correlated. However, this is no longer the case when the ratio between the reactance and resistance is close to one, which is often the case in low frequency railway power system. The consequence is that the voltage also has strong correlation with active power, implying that the voltage control also should consider active power. By considering the ratio between reactance and resistance the load sharing between converter units and stations can increase, as the regular voltage control law used today only considers reactive power.

The purpose of this paper is to present a modified voltage control law to reduce the risk of converter overload. The mathematical models of the converter, regular voltage control law and the modified voltage control law are presented in Section 2 and Section 3, respectively.

In a Swedish inspired low frequency railway power system, two system studies are done, presented in Section 4. The modified voltage control law and the regular voltage control law with different droop coefficient are studied. The results of the modified voltage control law and regular voltage control law, presented in Section 5, are compared to each other regarding active power generation, reactive power generation, system losses and voltages. The results are discussed and ideas on future work are presented in Section 6, especially on how to counter the negative impacts of the improved voltage controller on the low frequency railway power system. Finally, in Section 7, the conclusions are presented.

\section{CONVERTER MODEL}

\subsection{Converter angle at the railway side}

When active power flows from the three phase public power system to the low frequency railway power system via an RFC, a voltage phase shift is introduced. The voltage phase shift is the sum of the load angles of a three phase synchronous motor and a single phase synchronous generator $[5,6]$. The voltage phase shift is

$$
\psi=\frac{1}{3} \arctan \left(\frac{X_{M}^{q} P_{M}}{U_{M}^{2}+X_{M} q Q_{M}}\right)+\arctan \left(\frac{X_{G}^{q} P_{G}}{U_{G}^{2}+X_{M}^{q} Q_{G}}\right)
$$

where $X^{q}$ is the quadrature reactance. The active and reactive power is denoted $P$ and $Q$, respectively. The indices $\mathrm{M}$ and $\mathrm{G}$ stands for motor and generator, respectively. The load angle of the motor is divided by three to express the voltage phase shift in $16 \frac{2}{3} \mathrm{~Hz}$ angles.

In this model the reactance of the three phase step down transformer is added to the quadrature reactance of the motor and the reactance of the single phase step up transformer is added to the generator quadrature reactance.

Furthermore, in this model the RFC is assumed to be connected to a strong point in the three phase public power system, where the voltage magnitude and voltage angle $\theta_{50}$ are constant. The aforementioned voltage angle is the reference for the three phase motor.

The voltage angle $\theta_{50}$ is divided by three, due to the pole ratio between motor and generator, and the terminal angle of the generator expressed in $16 \frac{2}{3} \mathrm{~Hz}$ angle is:

$$
\theta=\frac{\theta_{50}}{3}-\psi
$$

The converter is assumed to be lossless, resulting in $P_{M}=P_{G}$. Since the three phase public power systems is strong, the reactive power production $Q_{M}$ of an RFC is assumed to be zero and voltage $U_{M}$ is assumed to be 1 p.u.

\subsection{Voltage control at the railway side}

The voltage of a converter is controlled such that with increased reactive power generation the voltage magnitude will drop. This results in an automatic load sharing between converters $[3,7]$. The voltage control law in p.u. is

$$
U_{g}=U_{0}-K_{U} \cdot Q_{G}
$$

where $U_{g}$ is the converter voltage at the railway side, $U_{0}$ is the no-load voltage and $K_{U}$ is a normalised droop coefficient.

\section{MODIFIED VOLTAGE CONTROL LAW \\ 3.1 Mathematical background}

The active power flow, $P_{k j}$ and the reactive power flow $Q_{k j}$, between node $k$ and $j$ (see Figure 1), with $Z_{k j}=R_{k j}+j X_{k j}$ is:

$$
\begin{gathered}
P_{k j}=\frac{\left(U_{k}^{2} R_{k j}-R_{k j} U_{k} U_{j} \cos \left(\theta_{k j}\right)+X_{k j} U_{k} U_{j} \sin \left(\theta_{k j}\right)\right)}{R_{k j}^{2}+X_{k j}^{2}} \\
Q_{k j}=\frac{\left(U_{k}^{2} X_{k j}-R_{k j} U_{k} U_{j} \sin \left(\theta_{k j}\right)-X_{k j} U_{k} U_{j} \cos \left(\theta_{k j}\right)\right)}{R_{k j}^{2}+X_{k j}^{2}} .
\end{gathered}
$$




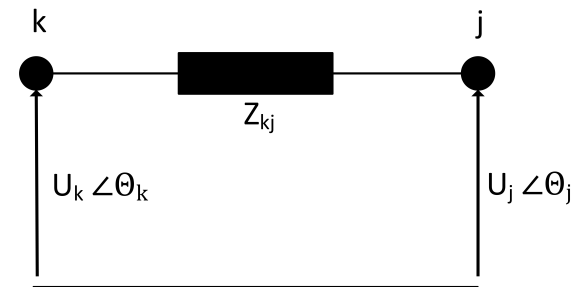

FIGURE 1. Node diagram.

According to Kirchhoff's current law, the sum of all currents in a node is zero. Therefore, there must be both an active power and reactive power balance in each node

$$
\begin{gathered}
P_{G k}-P_{D k}=\sum_{j=1}^{N} P_{k j} \\
Q_{G k}-Q_{D k}=\sum_{j=1}^{N} Q_{k j}
\end{gathered}
$$

where $P_{G k}$ and $Q_{G k}$ is the generated active power and reactive power at node $k$, respective. The consumed active power and the consumed reactive power at node $k$ is $P_{D k}$ and $Q_{D k}$, respectively and $N$ is the number of nodes in the system.

In a three phase power systems the reactances of the lines is often much larger than the resistances, and thus the resistance is neglected.

For small changes in $\theta_{k j}, \sin \left(\theta_{k j}\right) \approx \theta_{k j}$ and $\cos \left(\theta_{k j}\right) \approx 1$. When $X \gg R$ and with a small angle difference and voltage difference, then Equations (4) and (5), are simplified to

$$
\begin{aligned}
\theta_{k j} & \approx \frac{X_{k j} P_{k j}}{U_{k} U_{j}} \\
U_{k}-U_{j} & \approx \frac{X_{k j} Q_{k j}}{U_{k}} .
\end{aligned}
$$

As seen in Equation (8) active power and voltage angle are strongly correlated, and reactive power is strongly correlated with voltage magnitude as shown in Equation (9).

Controlling frequency and voltage magnitude respectively in a generator or an inverter with droop control [5, 8, 9] results active power and reactive power being decoupled and controlled independently as seen by Equations (10) and (11),

$$
\begin{array}{r}
f-f_{0}=-K_{f}\left(P-P_{0}\right) \\
U-U_{0}=-K_{V}\left(Q-Q_{0}\right)
\end{array}
$$

in which $f_{0}$ and $U_{0}$ are the no-load frequency and no-load voltage reference, respectively. The active power and reactive power reference are given by $P_{0}$ and $Q_{0}$, respectively. The coefficient $K_{f}$ and $K_{V}$ are drops coefficient for frequency and voltage, respectively.

However it should be noted that the voltage in railway power systems varies more than three phase power systems, and the ratio between reactance and resistance is often close to one. Therefore Equations (8) and (9) are no longer valid for low frequency railway power systems.

\subsection{New voltage control law}

As presented in [9] and [10], the resistance can't be neglected for medium and low voltage power systems. This is also true for low frequency railway systems as the nominal voltage are in between $12 \mathrm{kV}$ and $15 \mathrm{kV}$, and as the frequency is lower the reactances and resistances are often of same size. Thus, regulating the voltage will not only affect the reactive power, but will also have a strong influence on active power. The voltage control law according to Equation (3) can be improved by considering the resistance of the railway power system. To consider the resistance in the line impedance the authors of [9] propose an orthogonal linear rotational matrix $\mathbf{T}$,

$$
\mathbf{T}=\left(\begin{array}{cc}
\frac{X}{Z} & -\frac{R}{Z} \\
\frac{R}{Z} & \frac{X}{Z}
\end{array}\right)=\left(\begin{array}{cc}
\sin (\phi) & -\cos (\phi) \\
\cos (\phi) & \sin (\phi)
\end{array}\right)
$$

where $\phi=\arctan \left(\frac{R}{X}\right)$, showing that the ratio between the reactance and resistance is of importance. With $\mathbf{T}$ a modified active power $P^{\prime}$ and reactive power $Q^{\prime}$ can be defined as

$$
\begin{gathered}
\left(\begin{array}{l}
P^{\prime} \\
Q^{\prime}
\end{array}\right)=\mathbf{T}\left(\begin{array}{l}
P \\
Q
\end{array}\right) \\
P^{\prime}=\frac{X}{Z} P-\frac{R}{Z} Q \\
Q^{\prime}=\frac{R}{Z} P+\frac{X}{Z} Q .
\end{gathered}
$$

The modified voltage control law with consideration to the $\frac{X}{R}$ ratio of the line impedance is then

$$
U_{g}=U_{0}-K_{U} Q^{\prime}=U_{0}-K_{U}\left(\frac{R}{Z} P_{G}+\frac{X}{Z} Q_{G}\right)
$$

where $Q_{\mathrm{G}}$ and $P_{\mathrm{G}}$ are the reactive and active power generation from the converter unit, respectively. 


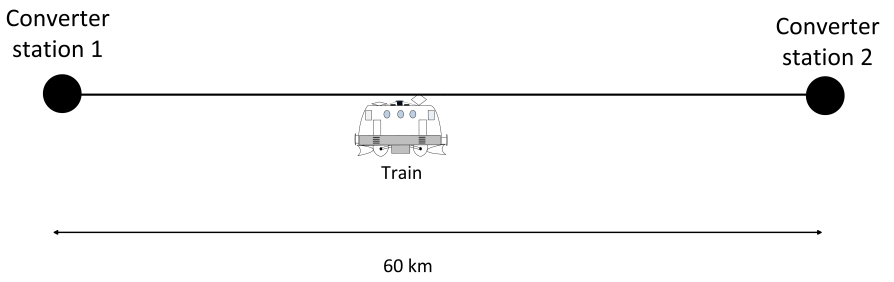

FIGURE 2. Electrical railway system investigated.

\section{CASE STUDIES}

Two system configuration have been studied, to investigate the effects of the modified voltage control law on the systems and compare the system when the regular voltage control law is used. The converters used are RFCs of the type Q48/Q49. The Q48/Q49 has a rated power of $10 \mathrm{MVA}$ and can be overloaded for six minutes with 14 MVA and has a short circuit capacity of 18 MVA.

The train starts at converter station 1 (CS 1) and travels to converter station 2 (CS 2). The distance between the converter stations is $60 \mathrm{~km}$ (37.7 miles). The system is divided into 30 nodes, where the distance between each node is $2 \mathrm{~km}(1.25$ miles). The system configurations investigated are:

1. Train consumption is constant and is $7 \mathrm{MW}$ at a power factor equal to one. Both converter stations have one Q48/Q49 each.

2. Train consumption is constant at $7 \mathrm{MW}$ and unity power factor. Converter station 1 has one Q48/Q49 installed and converter station 2 has six Q48/Q49 installed.

The systems are investigated for droop coefficients from $0 \%$ to $30 \%$, with an incremental increase of $2 \%$. The electrical power system studied is illustrated in Figure 2. The catenary system for power transfer is of BT (Booster Transformer) type, and an equivalent impedance of such system is used, see Table 1.

The software used to do the simulations is MatLab and GAMS. In MatLab the data of the system is given and in GAMS the simulation is done. The converter station model is based on Equations (1) - (3). Implementation of the modified voltage control law is done by replacing Equation (3) with Equation (16).

The data of the system is given in Table 1.

\section{RESULTS}

\subsection{Case 1}

The active and reactive power generation from converter station 1 and converter station 2 are presented in Figure 3 and 4, respectively. It is observed that the active power sharing between the converter stations has been slightly increased with the modified voltage control law, seen in Figure 3, as the active power has been more evenly distributed. More active power from converter

\begin{tabular}{c|c}
\hline Base Voltage, $U_{b}$ & $16.5 \mathrm{kV}$ \\
Base Power, $S_{b}$ & $5 \mathrm{MVA}$ \\
Catenary Impedance, $Z$ & $0.2+\mathrm{j} 0.2 \frac{\Omega}{\mathrm{km}}$ \\
Quadrature reactance motor, $X_{M}^{q}$ & $0.53 \mathrm{p.u}$. \\
Quadrature reactance generator, $X_{G}^{q}$ & $0.49 \mathrm{p} . \mathrm{u}$ \\
Transformer ratio motor & $6.3 / 22$ \\
Transformer ratio generator & $5.2 / 17$ \\
Transformer leakage reactance motor $X_{M}^{T}$ & $7.9 \%$ \\
Transformer leakage reactance generator $X_{G}^{T}$ & $4.2 \%$ \\
\hline
\end{tabular}

TABLE 1. System Data from [7].

station 2 is generated with the modified voltage control law for all positive droops when the train is close to $\mathrm{CS} 1$, thus relieving CS1.

In Figure 3 and 4 one can note that the loads are higher when the train is positioned in the middle between the converter stations, but the converter stations are lowly utilised. However, this is not a problem as the converter stations are not heavily loaded, and the intention of the modified voltage control law is to even out the loading of the converter stations.

As seen in Figure 4, the peak absolute values of reactive power is decreased, in a similar fashion as active power, but more pronounce. The voltage at converter station 1, shown in Figure 5, never goes above 1 p.u. when using the modified voltage control law, in contrast to the regular voltage control law. Note that the system is symmetric, this voltage behaviour of converter station 2 is similar, but opposite.

The increased active power generation from converter station 2 makes that the active power has to flow a longer distance resulting in an increase of losses. It is also observed that increasing the droop coefficient improves the load sharing, but the losses are increased and voltage at the train location are lower compared to the regular voltage control law, see Figures 6 and 7.

\subsection{Case 2}

The modified voltage control law increases the active and reactive power load sharing between the converters, for all droop coefficients. The larger station, in this case converter station 2 , increases its active power output when the train is positioned close to converter station 1 , thus relieving the station, see Figure 8.

Similar as in Case 1, the reactive power peaks are reduced for both station, see Figure 9. With the modified voltage control law, the contribution of power of the larger station is further increased as the contribution of the smaller station is reduced. As seen in Figures 10 and 12, the voltage is reduced at the train lo- 

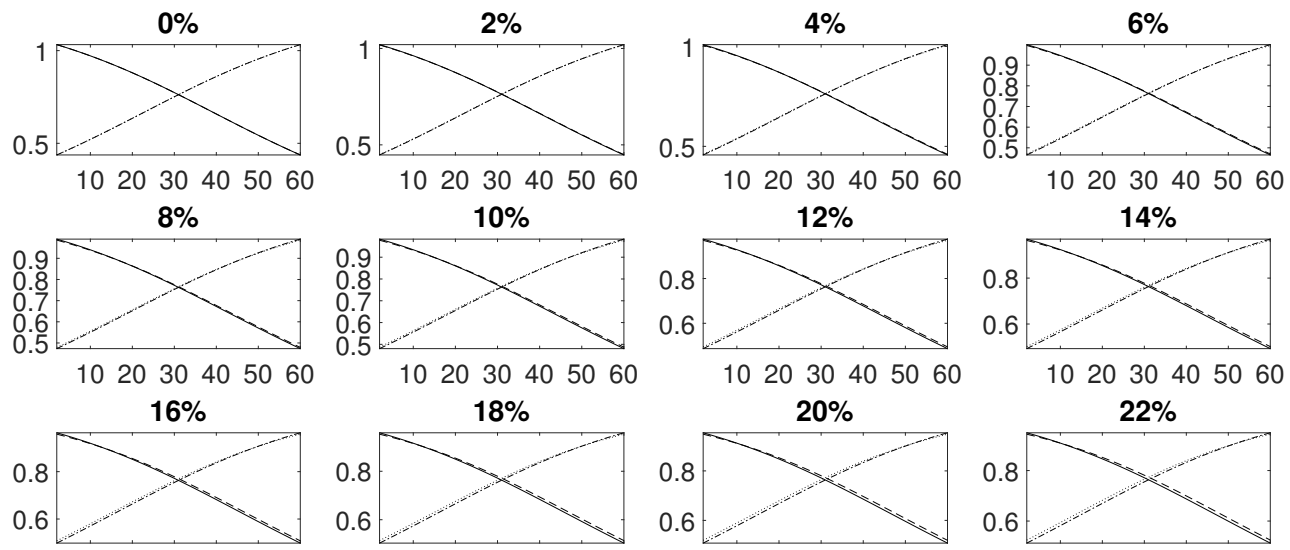

102030405060 $24 \%$

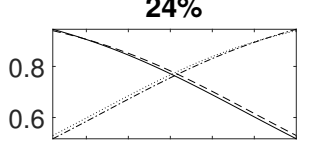

102030405060
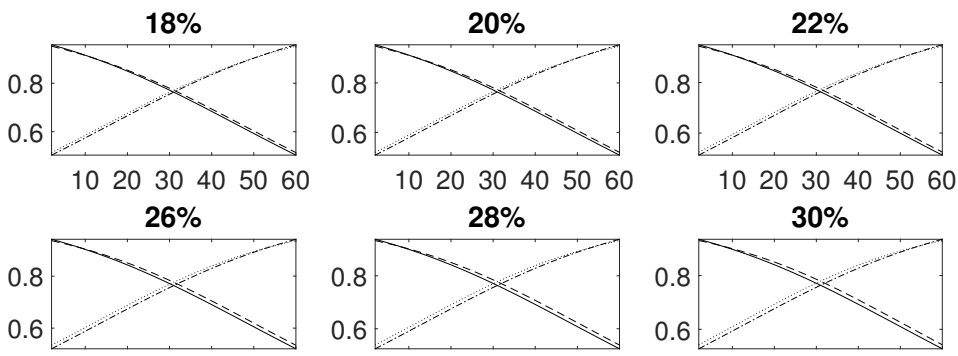

$10203040 \quad 5060$
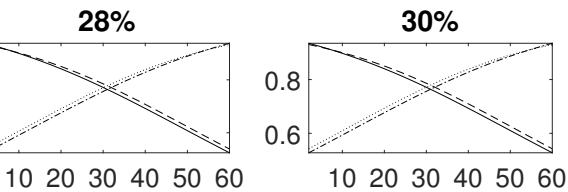

102030405060

FIGURE 3. Case 1: Active power generation (p.u.) from converter station 1 and 2 versus train location, with different droop coefficients. Sold line, regular voltage control law, CS 1. Dashed line, modified voltage control law, CS 1. Dash-dotted line, regular voltage control law, CS 2. Dotted line, modified voltage control law, CS 2.

cation and converter station 1. However, note also in Figure 12 that with the modified voltage control law, the voltages does not exceed the no-load voltage. The losses increase slightly with the modified voltage control law, as seen in Figure 11, as the power need to flow a longer distance. It is also observed that the losses are only larger when the train is further away from converter station 2; when the train gets closer to station 2 the losses become equal for both the regular voltage control law and the modified voltage control law.

\section{DISCUSSION}

A simple model is used for the train in the presented case studies; in reality the behaviour of the trains is more complex. For example for some trains active and/or reactive power show a voltage dependency. Thus a more complex train model should be used to study the impact of the modified voltage control law on these types of trains.

As seen in the simulations, the losses increase with the modified voltage control law and thus reducing the efficiency of the rail power system. It also noticed that the droop coefficients play an important role: a higher coefficient leads to a evenly distributed load sharing but at the cost of increased losses and lower voltage at the catenary. A possible approach is to find both an optimal no-load voltage and optimal droop coefficient which could counteract the negative impact of the modified voltage control law. It is likely that the no-load voltages can be increased since the overvoltages for the regular voltage control law noticed in Figures 5 and 12 are removed with the modified voltages control.

The strength of the modified voltage control law compared to the regular voltage control law is that converter stations that are heavily loaded now get relieved when the train consumes only active power. However at the same time, consideration should be taken when trains are regenerating as it can lead to overvoltages at the converter stations. Thus requiring further investigation.

Another aspect to be considered is the load sharing inside a converter station. Often converters of different sizes are operating in parallel in the same station. The modified voltage control law should influence the active power and reactive power load sharing between the converter units positively during dynamics, and its benefits should be investigated.

For asynchronous-synchronous low frequency railway power systems, the consideration of the low ratio of $\frac{R}{X}$ would be interested to study for both frequency and voltage control. Also here it may lead to an improvement of both active and reactive load sharing between converter units and converter stations. 

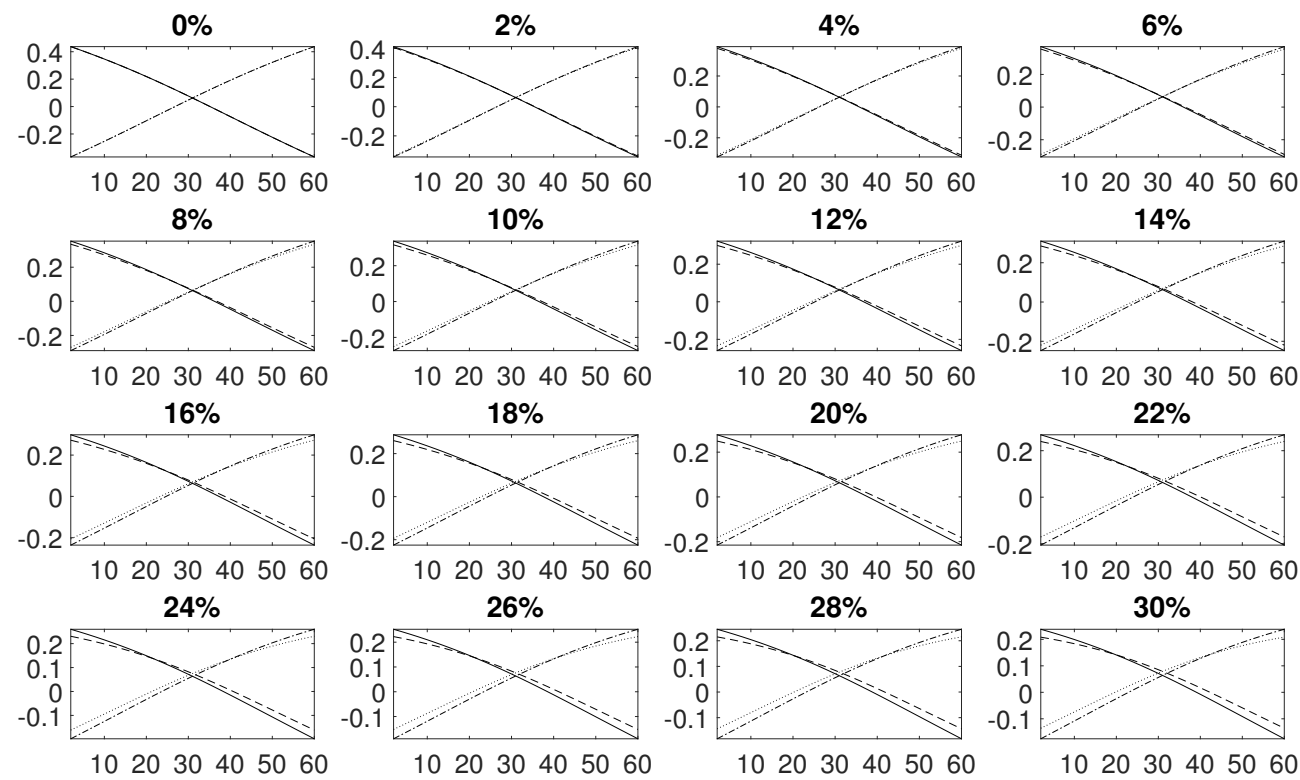

102030405060

102030405060

102030405060

FIGURE 4. Case 1: Reactive power generation (p.u.) from converter station 1 and 2 versus train location, with different droop coefficients. Sold line, regular voltage control law, CS 1. Dashed line, modified voltage control law, CS 1. Dash-dotted line, regular voltage control law, CS 2. Dotted line, modified voltage control law, CS 2.

\section{CONCLUSIONS}

The proposed voltage control law has been investigated for different load positions and converter station relative strength. and compared to the regular voltage control law. It is concluded that the load sharing between converter stations has been improved when the converter stations are of the same size and also when they are of different size. However, losses are increased and voltages are lower with the improved voltage control. These negative impacts could be counteracted by increasing the no-load voltage and finding a proper droop coefficient.

\section{REFERENCES}

[1] Steimel, A., 2008. Electric Traction - Motive Power and Energy Supply. Oldenbourg Industrieverlag $\mathrm{GmbH}, \mathrm{Mu}-$ nich.

[2] Östlund, S., 2012. Electric Railway Traction. School of Electrical Engineering, Royal Insitute of Technology, Stockholm.

[3] Abrahamsson, L., Skogberg, R., Östlund, S., Lagos, M., and Söder, L., 2015. "Identifying Electrically Infeasible Traffic Scenarios on the Iron Ore Line; Applied on the Present-Day System, Converter Station Outages, and Optimal Locomotive Reactive Power Strategies”. In 2015 Joint Rail Conference, ASME.
[4] Zynovchenko, A., Haubrich, H.-J., and Treige, P., 2005. "Converter control and stability of the $110-\mathrm{kV}$ railway grid increasing use of the static frequency converters". In 2005 European Conference on Power Electronics and Applications, IEEE.

[5] Machowski, J., Bialek, J. W., and Bumby, J. R., 2008. POWER SYSTEM DYNAMICS - Stability and Control, second ed. John Wiley \& Sons, Ltd.

[6] Olofsson, M., 1996. "Optimal Operation of the Swedish Railway Electrical System - An application of Optimal Power Flow". Phd thesis, Royal Institute of Technology.

[7] Abrahamsson, L., 2008. "Railway Power Supply Models and Methods for Long-term Investment Analysis". Licentiate thesis, KTH, Electric Power Systems.

[8] Kundur, P., 1994. Power System Stability and Control. McGraw-Hill, Inc.

[9] De Brabandere, K., Bolsens, B., Van den Keybus, J., Woyte, A., Driesen, J., and Belmans, R., 2007. "A Voltage and Frequency Droop Control Method for Parallel Inverters". IEEE Transactions on Power Electronics, 22(4), jul, pp. 11071115.

[10] Engler, A., and Soultanis, N., 2005. "Droop control in LVgrids". In 2005 International Conference on Future Power Systems, IEEE. 


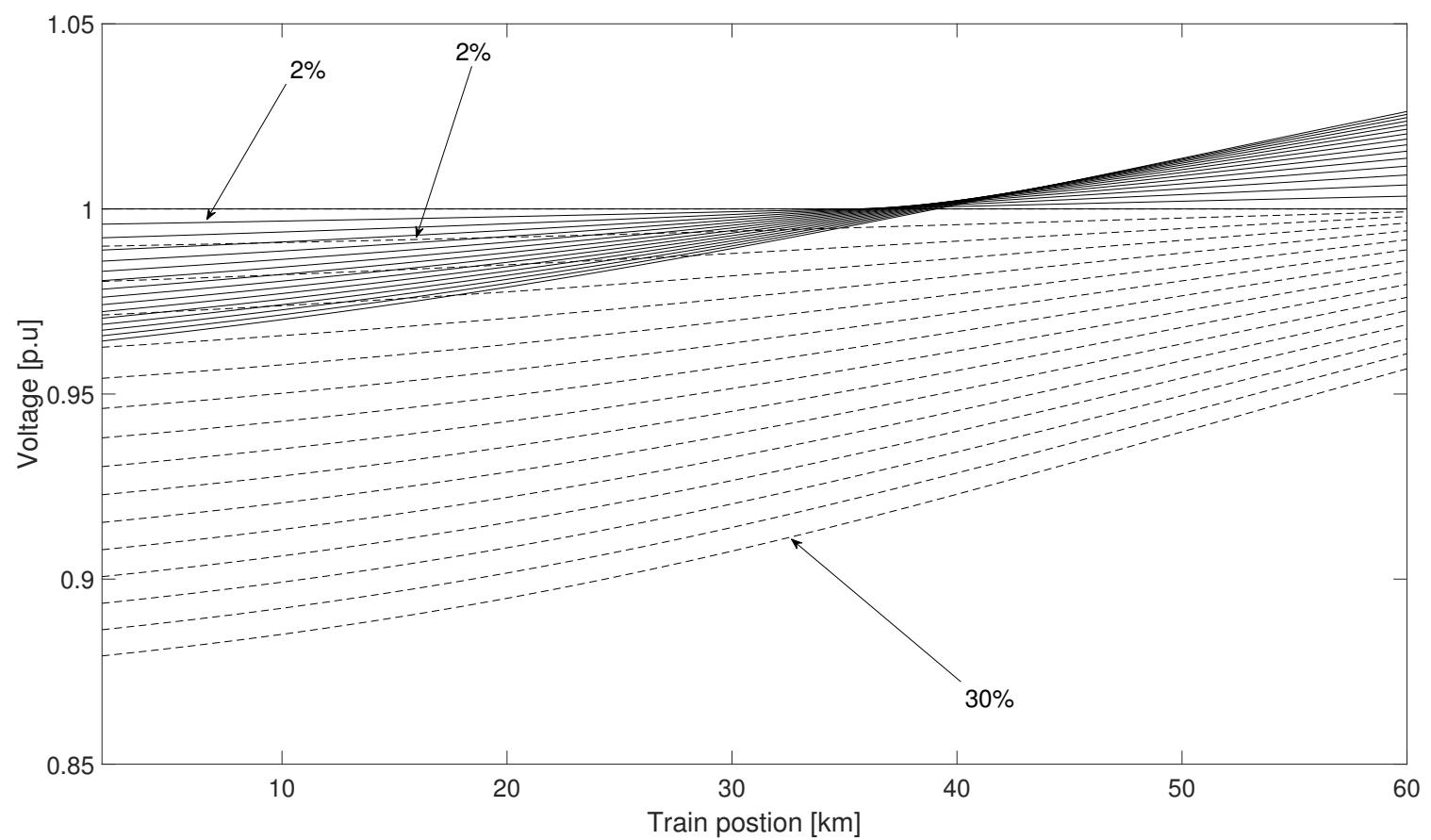

FIGURE 5. Case 1: Voltage (p.u.) at converter station 1 versus train location, with different droop coefficients. Solid line, regular voltage control law. Dotted line, modified voltage control law.
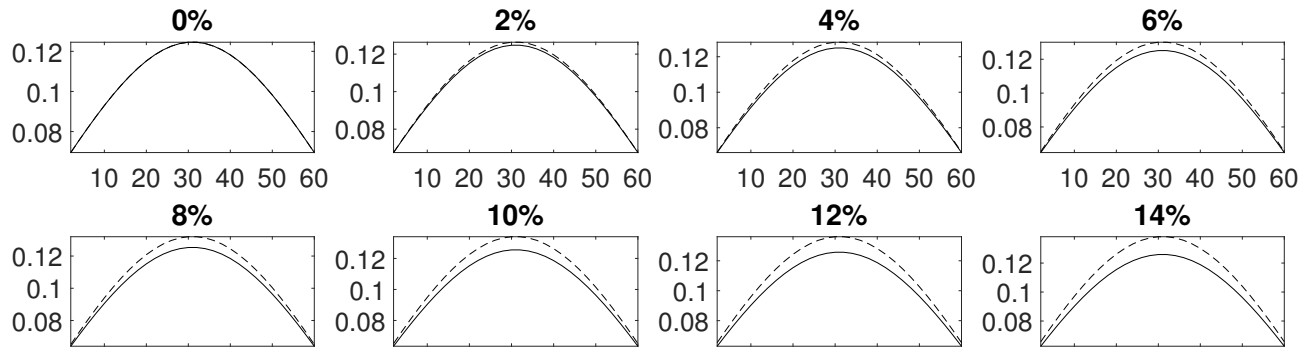

102030405060

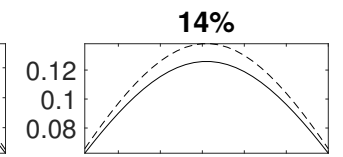

02030405060

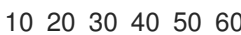

102030405060

102030405060

$16 \%$

$18 \%$
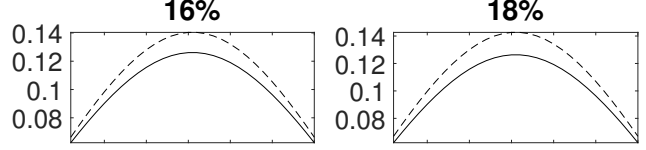

$20 \%$
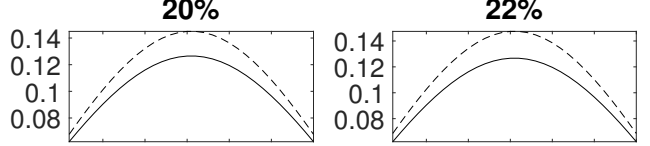

102030405060

102030405060

102030405060

$28 \%$
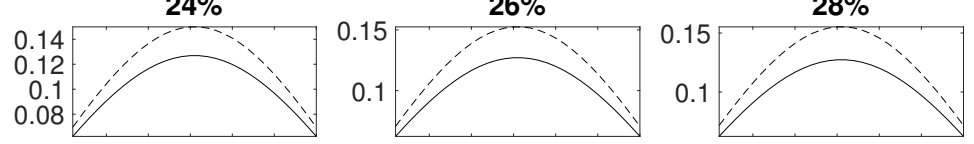

102030405060

$30 \%$

102030405060

102030405060

102030405060

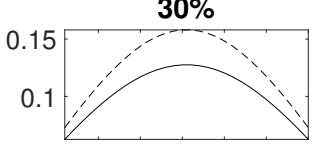

102030405060

FIGURE 6. Case 1: Active power losses (p.u.) versus train location, with different droop coefficients. Dashed line, modified voltage control law. Solid line, regular voltage control law. 


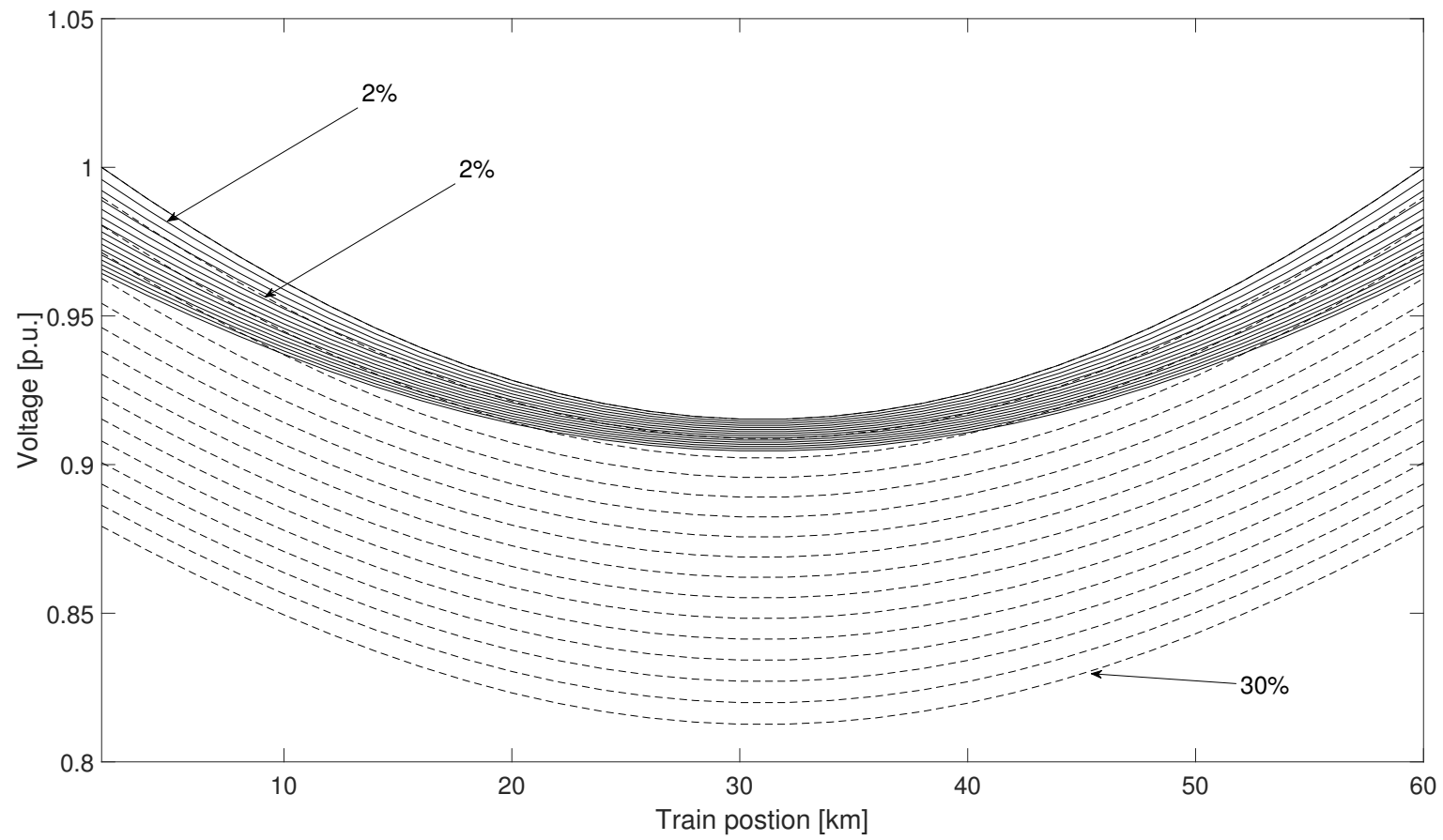

FIGURE 7. Case 1: Voltage (p.u.) at train location, with different droop coefficients. Dashed line, modified voltage control law. Solid line, regular voltage control law.

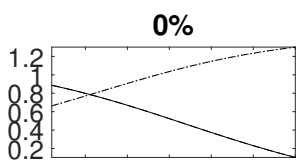

102030405060

$8 \%$

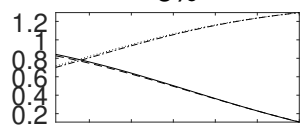

102030405060 $16 \%$

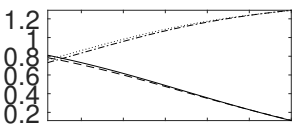

102030405060 $24 \%$

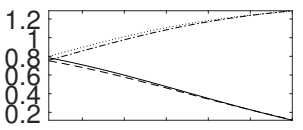

102030405060

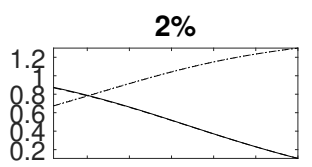

$102030 \quad 405060$

$10 \%$

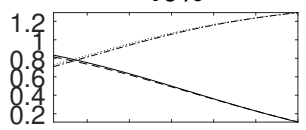

102030405060

$18 \%$

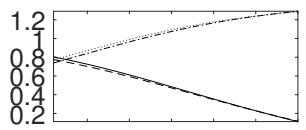

102030405060

$26 \%$

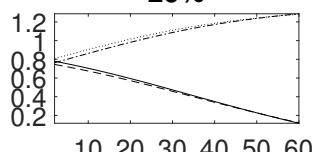

102030405060

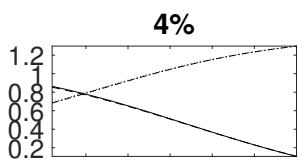

102030405060

$12 \%$

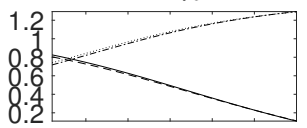

102030405060

$20 \%$

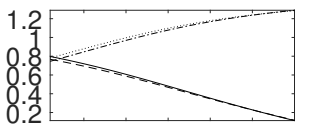

102030405060

$28 \%$

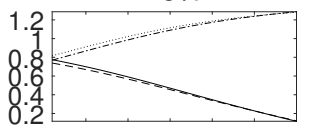

102030405060

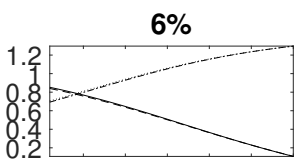

102030405060

$14 \%$

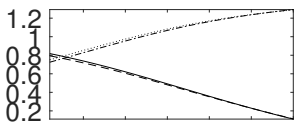

102030405060

$22 \%$

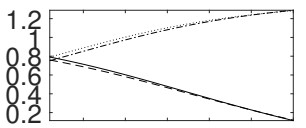

102030405060

$30 \%$

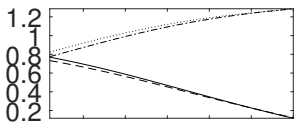

102030405060

FIGURE 8. Case 2: Active power generation (p.u.) from converter station 1 and 2 versus train location, with different droop coefficients. Sold line, regular voltage control law, CS 1. Dashed line, modified voltage control law, CS 1. Dash-dotted line, regular voltage control law, CS 2. Dotted line, modified voltage control law, CS 2. 

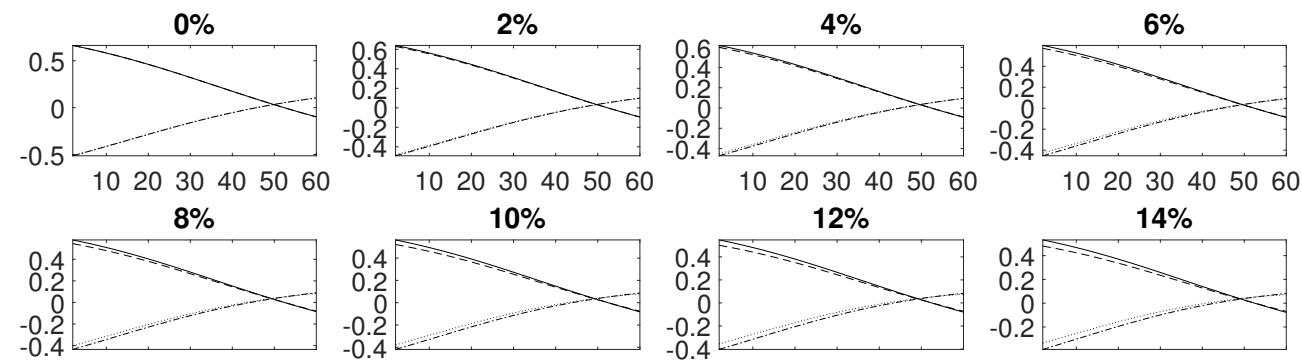

102030405060
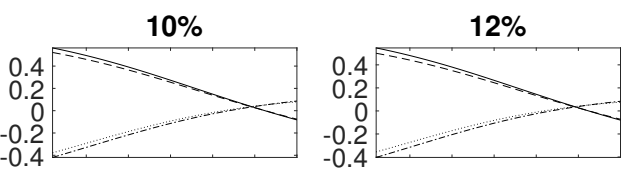

$-0.2$

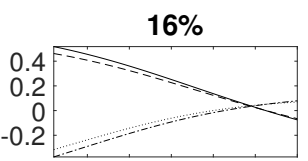

102030405060

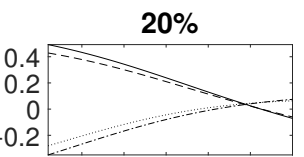

102030405060

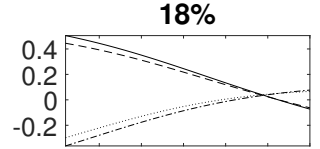

102030405060

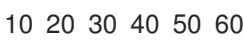

102030405060
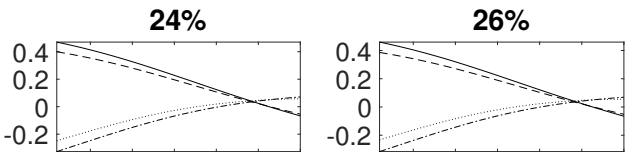

102030405060

102030405060

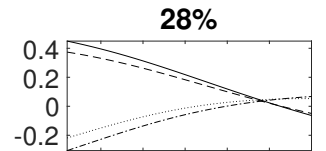

102030405060
$14 \%$

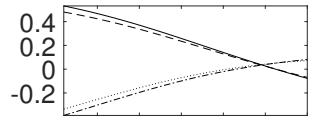

102030405060

$22 \%$

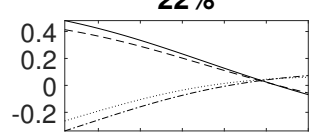

102030405060

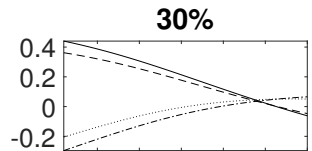

102030405060

FIGURE 9. Case 2: Reactive power generation (p.u.) from converter station 1 and 2 versus train location, with different droop coefficients. Sold line, regular voltage control law, CS 1. Dashed line, modified voltage control law, CS 1. Dash-dotted line, regular voltage control law, CS 2. Dotted line, modified voltage control law, CS 2.

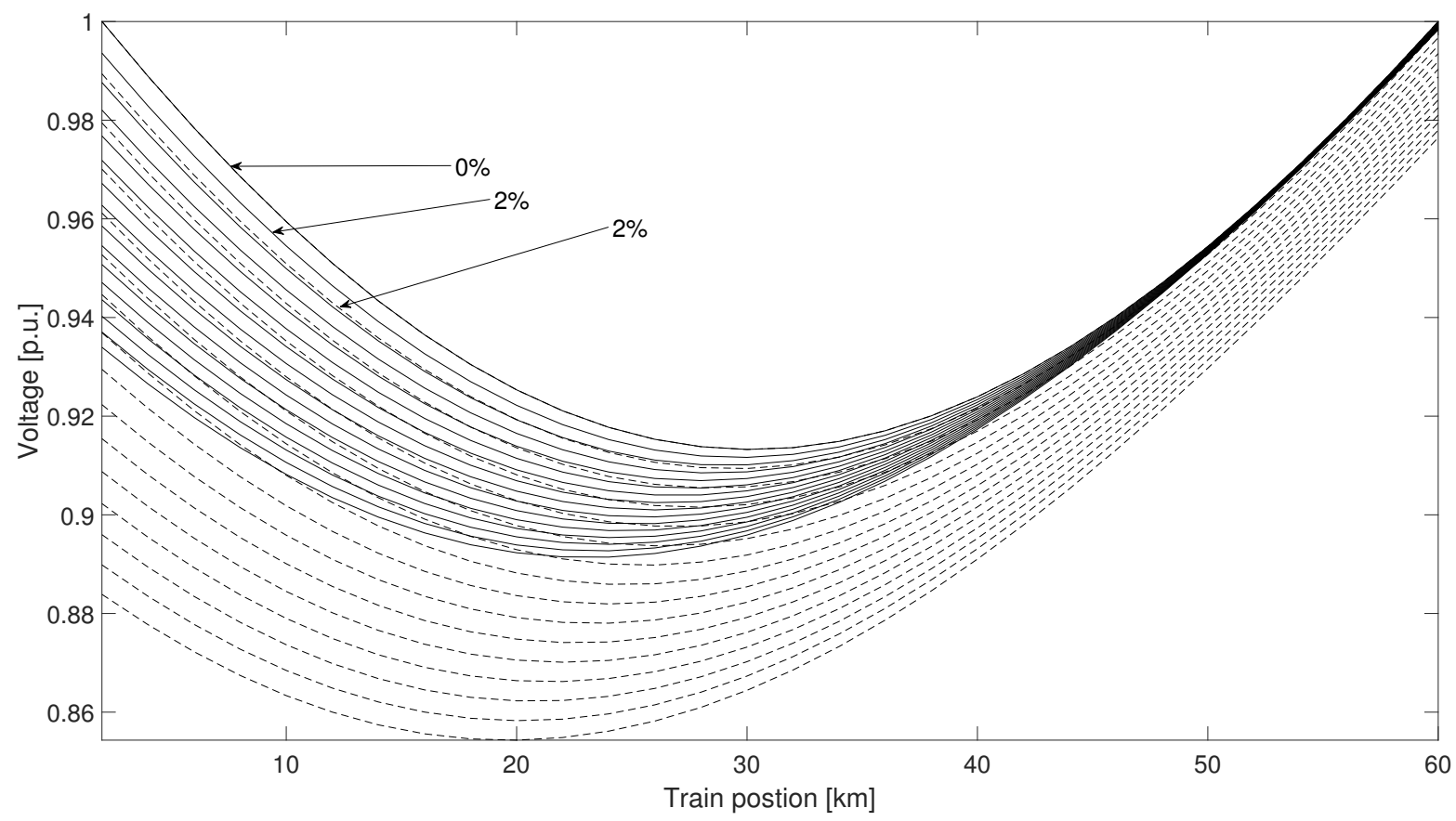

FIGURE 10. Case 2: Voltage (p.u.) at train location, with different droop coefficients. Dashed line, modified voltage control law. Solid line, regular voltage control law. 

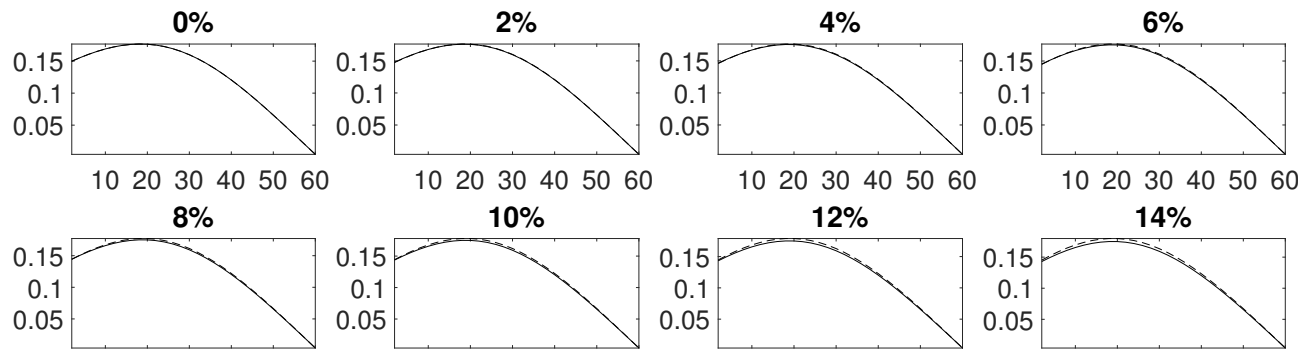

102030405060

102030405060

102030405060
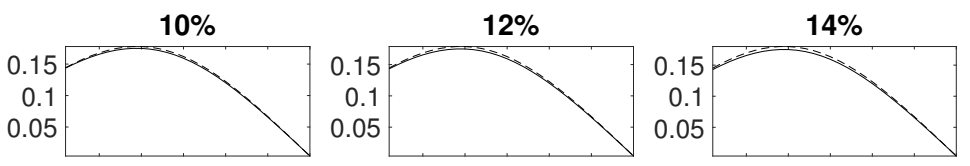

102030405060

102030405060

102030405060

102030405060
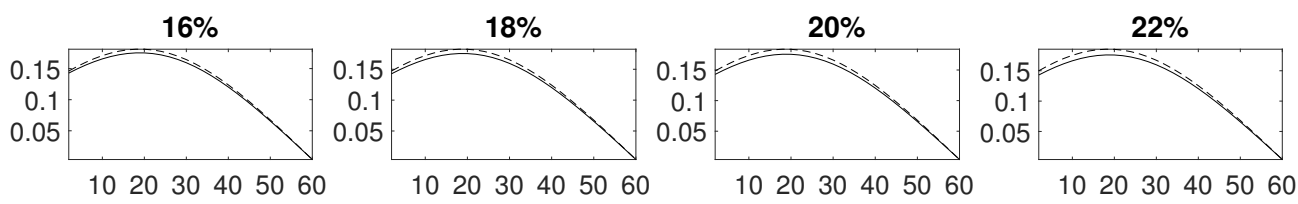

102030405060

$102030 \quad 405060$

102030405060

$24 \%$

$26 \%$
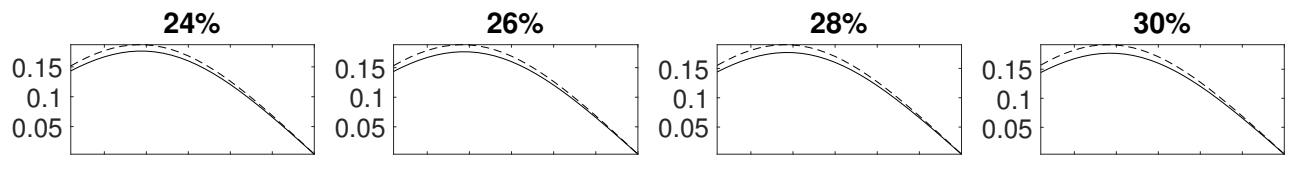

$102030 \quad 405060$

$102030 \quad 405060$

$102030 \quad 405060$

102030405060

FIGURE 11. Case 2: Active power losses (p.u.) versus train location, with different droop coefficients. Dashed line, modified voltage control law. Solid line, regular voltage control law.

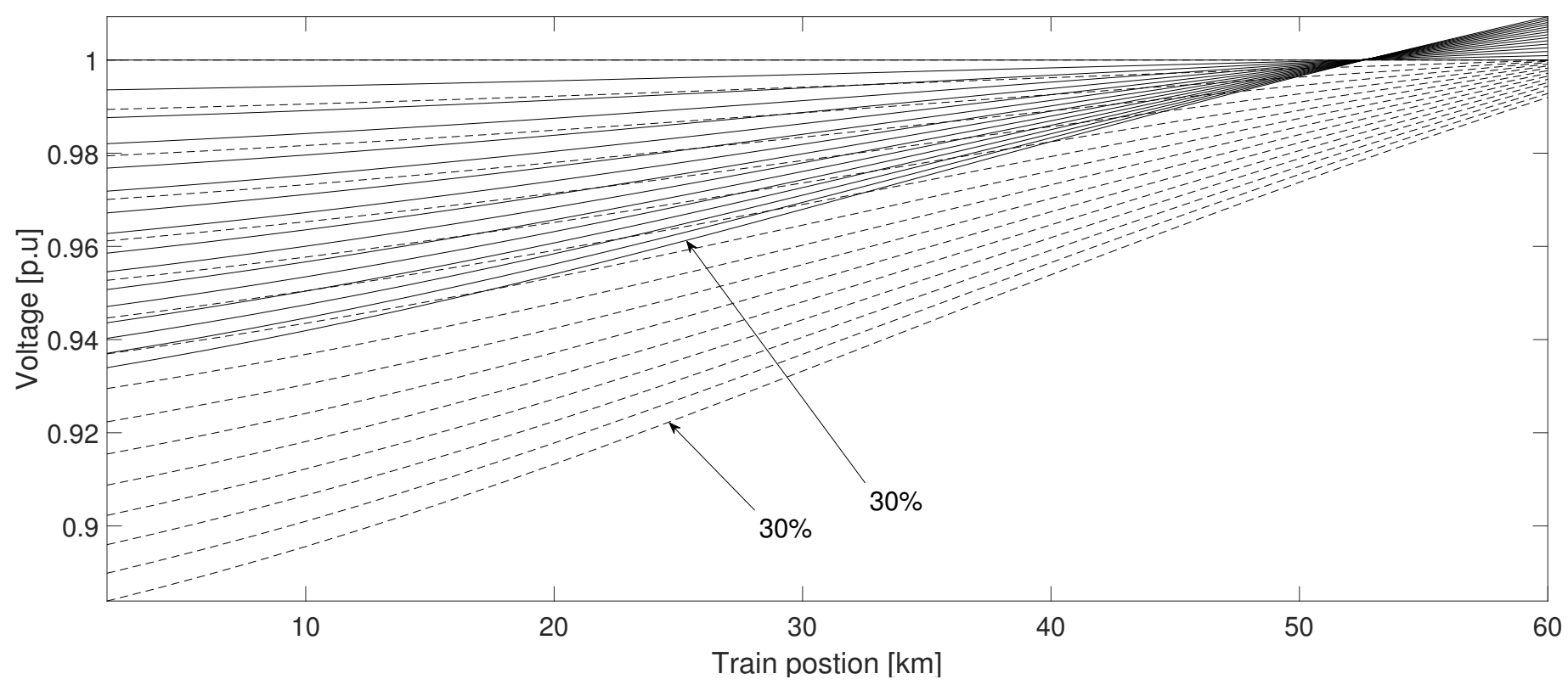

FIGURE 12. Case 2: Voltage (p.u.) at converter station 1 versus train location, with different droop coefficients. Solid line, regular voltage control law. Dotted line, modified voltage control law. 